OPEN ACCESS

Edited by:

Jose Eduardo Villarreal Barajas,

Royal Devon and Exeter Hospital,

United Kingdom

Reviewed by:

Yuanzeng Min,

University of Science and Technology

of China, China

Peng Mi,

Sichuan University, China

Xin Pang,

First Affiliated Hospital of Zhengzhou

University, China

*Correspondence:

Bo Li

liboer2002@126.com

Jingdong $L$

Li-Jingdong@hotmail.com

Jingsong Mao

maojingsong163@163.com

Gang Liu

gangliu.cmitm@xmu.edu.cn

${ }^{+}$These authors have contributed equally to this work

Specialty section:

This article was submitted to

Radiation Oncology,

a section of the journal

Frontiers in Oncology

Received: 04 August 2021 Accepted: 23 September 2021

Published: 08 October 2021

Citation:

He $P$, Guan $S$, Ren E, Chen $H$, Chen $H$, Peng Y, Luo B, Xiong Y, Li B, Li J, Mao J and Liu G (2021) Precision Interventional Brachytherapy: A Promising Strategy Toward Treatment of Malignant Tumors.

Front. Oncol. 11:753286. doi: 10.3389/fonc.2021.753286

\section{Precision Interventional} Brachytherapy: A Promising Strategy Toward Treatment of Malignant Tumors

\author{
Pan He ${ }^{1 \dagger}$, Siwen Guan ${ }^{1 \dagger}$, En Ren ${ }^{1}$, Hongwei Chen ${ }^{1}$, Hu Chen ${ }^{1}$, Yisheng Peng ${ }^{2}$, Bin Luo ${ }^{2}$, \\ Yongfu Xiong ${ }^{3}$, Bo $\mathrm{Li}^{2 *}$, Jingdong $\mathrm{Li}^{3 *}$, Jingsong Mao ${ }^{1,4^{*}}$ and Gang Liu ${ }^{1 *}$ \\ ${ }^{1}$ State Key Laboratory of Molecular Vaccinology and Molecular Diagnostics, Center for Molecular Imaging and Translational \\ Medicine, School of Public Health, Xiamen University, Xiamen, China, ${ }^{2}$ Department of General Surgery (Hepatobiliary \\ Surgery), The Affiliated Hospital of Southwest Medical University, Luzhou, China, ${ }^{3}$ Institute of Hepato-Biliary-Intestinal \\ Disease, Department of Hepatobiliary Surgery, Affiliated Hospital of North Sichuan Medical College, Nanchong, China, \\ ${ }^{4}$ Department of Radiology, Xiang'an Hospital of Xiamen University, Xiamen, China
}

Precision interventional brachytherapy is a radiotherapy technique that combines radiation therapy medicine with computer network technology, physics, etc. It can solve the limitations of conventional brachytherapy. Radioactive drugs and their carriers change with each passing day, and major research institutions and enterprises worldwide have conducted extensive research on them. In addition, the capabilities of interventional robotic systems are also rapidly developing to meet clinical needs for the precise delivery of radiopharmaceuticals in interventional radiotherapy. This study reviews the main radiopharmaceuticals, drug carriers, dispensing and fixation technologies, and interventional robotic precision delivery systems used in precision brachytherapy of malignant tumors. We then discuss the current needs in the field and future development prospects in high-precision interventional brachytherapy.

Keywords: precision brachytherapy, interventional surgery, radiopharmaceuticals, drug delivery, tumor treatment

\section{INTRODUCTION}

Malignant tumors (MT) are among the most severe diseases threatening human health conditions in the 21st century. MT are also the focus of substantial research worldwide (1-3). The primary treatment modalities for MT include surgical treatment, radiotherapy, chemotherapy, immunotherapy, as well as the newly developed photothermal, photodynamic, and sounddynamic therapies (4-7). Of these, comprehensive surgical treatment mainly based on surgical treatment plays a crucial role in the treatment of MT (8). However, it is often difficult, if not impossible, to diagnose MT early. Accordingly, by the time tumors are found, patients are in the middle and late stage of the disease, and the rate of surgical resection and radical cure is thus low (911). Therefore, tools to improve the therapeutic effect of existing treatments on patients with MT is an urgent problem to be solved and a hot research topic at the moment.

Radiotherapy is one of the three most-common MT treatment modalities, along with surgery and chemotherapy. It uses ionizing radiation to kill tumor cells and shrink tumors $(12,13)$. Versus 
surgery and chemotherapy, radiotherapy uses colorless, odorless, invisible, and non-invasive radiation to kill tumor cells. It is widely used in the radical curative treatment or palliative treatment of primary MT and metastatic tumors. Approximately $70 \%$ of patients with malignancy need radiation therapy at various stages of their treatment, of which $70 \%$ are radical radiotherapy. Radiotherapy accounts for about $40 \%$ of cured malignancies (14). The goal of radiotherapy is to maximize the radiation dose to the lesion (target) area for a long time and kill tumor cells while preventing or protecting surrounding normal tissues or organs from unnecessary radiation exposure, thus providing the required special protection to some vital organs such as the brainstem, spinal cord, kidney, gonads, etc. (15).

Traditional radiotherapy techniques, such as Co-60 teletherapy with poor precision and limited radiotherapy effectiveness, only achieve the primary stage of the radical curative treatment of the tumor, and also cause temporary or permanent damage to normal tissues and organs $(16,17)$. Interventional medicine has progressed particularly rapidly and led to the development and use of interventional radiotherapy techniques, in which radiopharmaceuticals are directly injected into the lesions through intubation and injection to enrich the concentration of the drugs in the lesions. This enables precise and targeted delivery of radiopharmaceuticals and overcomes the deficiency of traditional Co-60 teletherapy (18-20). However, there are still a series of problems to be solved in using radiopharmaceuticals in interventional radiotherapies, such as the selection of radiopharmaceuticals and their carriers, the uniform distribution and long-term fixation. In addition, interventional internal radiation therapy uses padding and manual implantation of radioactive drugs by doctors with their bare hands. This can prevent accurate calculations and evaluation of the injection pressure. Surgeons are thus exposed to radiation hazards. There is also an increase in patients with radioactive leaks and absorbed dose by non-target organs when the implantation operation time is too long and the injection pressure is too high. In addition, most implantation of radiopharmaceuticals is performed under computed tomography (CT) guidance. Although CT offers high resolution, it has problems such as being unable to be used in real-time dynamic navigation, with repeat punctures or offer precise delivery.

Precision interventional brachytherapy (PIBT) is a gradually developed radiotherapy technique that combines radiotherapy medicine with computer network technology, physics, etc. to address the limitations of conventional internal radiotherapy (21). For example, the most advanced radiotherapy equipment in vascular interventional robotic surgery is accurate to millimeters with very low side effects. This increases the accuracy of radiotherapy and thus application in clinical practice. Interventional doctors use catheters, guide wires, and other interventional devices to eliminate the heavy burden of lead protective aprons and reduce radiation exposure. Robot-assisted percutaneous coronary intervention (PCI) surgery can reduce radiation exposure by $97 \%$ (22). In addition, dispensing and fixation technologies for radiopharmaceuticals and drug carriers and precise delivery systems are active research topics. This paper reviews the main radiopharmaceuticals $\left({ }^{131} \mathrm{I},{ }^{125} \mathrm{I},{ }^{177} \mathrm{Lu}\right.$, etc.), drug carriers (Lipiodol, Microspheres, Hydrogels, etc.), dispensing and fixation technologies (SHIFT, Medrad, etc.), and interventional robotic precision delivery systems used in malignant tumor PIBT (Figure 1). It also discusses the current needs of the field and future development prospects.

\section{COMMONLY USED RADIONUCLIDES}

As early as 1901, Pierre and Marie Curie used small radium tubes for the first time to treat malignant tumors marking the birth of endoradiotherapy technology $(23,24)$. In 1970, Felix Mick developed a low-energy ${ }^{125} \mathrm{I}$ particle source containing iodine particles encapsulated in capsules and placed in a titanium tube. The ${ }^{125}$ I was subsequently used for endoradiotherapy of prostate, liver, and lung cancer; its efficacy was clinically proven and widely recognized over the following decades (25-27). Versus conventional external radiotherapy, permanent ${ }^{125} \mathrm{I}$ seed implantation has its unique advantages. The first is that the release of $\mathrm{x}$-rays, $\gamma$-rays, and other types of radiation is from the inside of the tumor tissue, causing DNA damage to tumor cells (28). As a result, the irradiation route does not need to pass through normal tissues to reach the target area. The dose distribution follows the inverse square law with an increase as distance decreases. Thus, the surrounding normal tissues are well protected, and the incidence of complications is low. Second, the local dose is high. The intensity of the implanted radioactive source is small, and the effective irradiation radius is short; thus, a higher radiation dose can be applied to the tumor target area (29).

The commonly used nuclides in nuclear medicine mainly include ${ }^{125} \mathrm{I},{ }^{103} \mathrm{Pd},{ }^{169} \mathrm{Yb},{ }^{198} \mathrm{Au},{ }^{131} \mathrm{Cs},{ }^{137} \mathrm{Cs},{ }^{192} \mathrm{Ir},{ }^{60} \mathrm{Co}$, etc. (30). New nuclides such as ${ }^{241} \mathrm{Am},{ }^{152} \mathrm{Cf},{ }^{26} \mathrm{Ra}$, and ${ }^{145} \mathrm{Sm}$ have recently attracted considerable attention. They have been used in clinical practice, but the most commonly used nuclides are ${ }^{125} \mathrm{I}$ and ${ }^{103} \mathrm{PD}$, which have become essential to traditional external radiotherapy (31). The most common models of brachytherapy source models seeds are Pharma Seed BT-125-1 or BT-125-2 (Syncor Pharmaceuticals Inc, Golden, CO, USA), ADVANTAGE ${ }^{\mathrm{TM}}$ Pd-103 IAPd-103A (IsoAid LLC, Port Richey, FL, USA), Prospera I-125-Med363 (North American Scientific, Inc., Chatsworth, CA, USA), Best ${ }^{\circledR}$ I-125 (Best Medical International, Inc., Springfield, VA, USA), and Type $6711{ }^{125} \mathrm{I}$ particles (HTA Co., Ltd., Beijing, China). The diameter of ${ }^{125} \mathrm{I}$ particles is $0.8 \mathrm{~mm}$, and the length is $4.5 \mathrm{~mm}$; the wall thickness of the enveloping titanium tube is $0.05 \mathrm{~m}$ (the source core is $\varphi$ $0.5 \mathrm{~mm} \times 3.0 \mathrm{~mm}$ to adsorb ${ }^{125} \mathrm{I}$ silver rod, which is suitable for killing tumor cells with slow growth). Although radionuclide particle therapy for tumors has high safety and achieves sound therapeutic effects, there are still some constraints, such as selecting radionuclide particles for the precise treatment of tumors with different proliferation rates to obtain the maximum killing effect. Second, there are complications and 


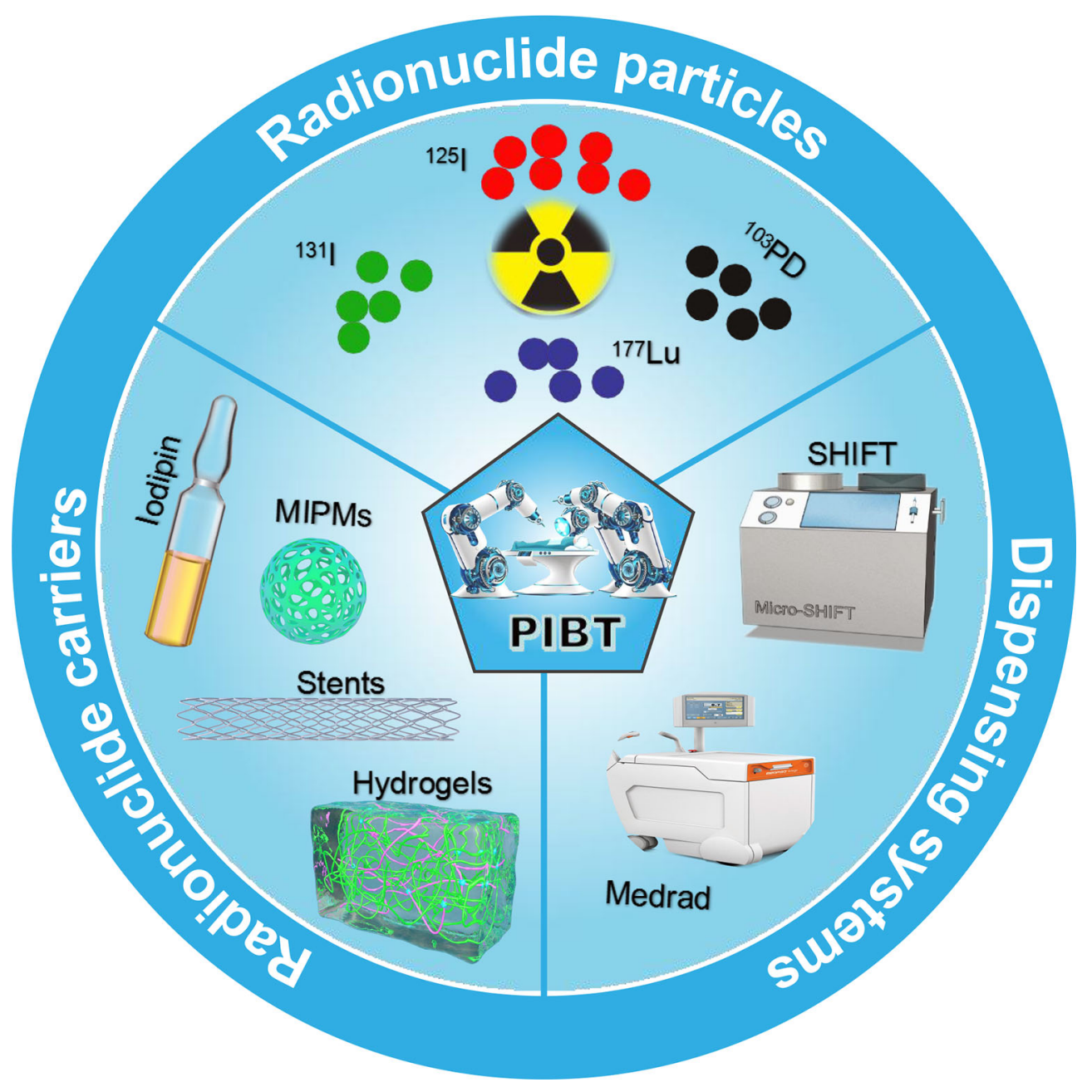

FIGURE 1 | Schematic showing radionuclide particles, radionuclide carriers, and dispensing systems commonly used in interventional brachytherapy.

adverse reactions after particle implantation. Finally, there is a need to study further the efficacy evaluation methods of particle implantation combined with external radiotherapy.

\section{CARRIERS OF RADIONUCLIDES FOR INTERVENTIONAL BRACHYTHERAPY}

\section{lodized Oil}

Lipiodol is the most commonly used carrier for radionuclide drugs because it is easy to inject and selectively deposited. For example, ${ }^{131}$ I-labeled lipiodol has been proven to be clinically effective and is commercially available (32). However, ${ }^{131}$ I suffers from high-energy gamma photon emission (364 keV, 81\%) (33), and the radioactivity yield of ${ }^{131} \mathrm{I}$-labeled lipiodol is also poor. Due to its suitable decay properties $\left(\mathrm{T}^{1 / 2}=6.73\right.$ days, $\mathrm{E} \beta$ ( Max) $=0.49 \mathrm{MeV}, \mathrm{E} \gamma=208 \mathrm{KeV}[11 \%])$, the half-life of ${ }^{177} \mathrm{Lu}$ is comparable to that of ${ }^{131} \mathrm{I}$ without significant decay loss.
The relatively low abundance of low-energy gamma photons can be used for simultaneous scintillation imaging and dosimetry studies without a significant additional dose burden to the patient. Thus, it is a feasible substitute of ${ }^{131} \mathrm{I}$ in lipiodol for liver cancer radiotherapy $(34,35)$. However, water-soluble nuclide particles are difficult to disperse stably in lipiodol for a long time. For instance, Suresh et al. treated a rat orthotopic liver tumor model with ${ }^{177}$ Lu-labeled lipophilic 8-hydroxy-quinoline mixed with lipiodol by a traditional method. They found that it was prone to radioactive leakage and deposited in bone tissue (36). This limited the clinical application of lipiodol with ${ }^{177} \mathrm{Lu}-$ labeled. Therefore, it is an important direction and hot topic for future research to develop efficient, simple, and stable lipiodol/ nuclide preparations and obtain stable and long-term interventional radiotherapy.

\section{Microspheres}

Recently, some progress has been made in developing methods for the preparation of interventional radioactive microsphere 
embolization materials (37). For example, Arranja et al. (38) dispersed solid acetylacetone holmium microspheres (HO2 (Acac) 3-MS) in $\mathrm{NaH}_{2} \mathrm{PO}_{4}$ or $\mathrm{NaOH}$ solutions and incubated at room temperature for $2 \mathrm{~h}$ to obtain two new inorganic microspheres. They then exchanged them with phosphate or hydroxyl ions through acetylacetone to obtain $\mathrm{Ho}(\mathrm{OH})$ 3-MS and $\mathrm{Ho}(\mathrm{OH})$ 4-MS. After preparing HopO4-MS and $\mathrm{Ho}(\mathrm{OH})$ $3 \mathrm{MS}$, the stable isotope ${ }^{166} \mathrm{Ho}$ was partially converted into radioactive ${ }^{166} \mathrm{Ho}$ by neutron activation, and high activity radioactive microspheres were obtained. Zielhuis et al. (39) used elemental holmium combined with the carboxylic acid group of alginate polymer through electrostatic action to obtain alginate microspheres loaded with holmium. Finally, ${ }^{166} \mathrm{Ho}$ was added into calcium-hardened alginate microspheres to obtain microspheres with high radiochemical stability ( $94 \%$ after $48 \mathrm{~h}$ incubation in human serum). Ma et al. (40) performed ${ }^{131}$ I labeling using gelatin microspheres as carriers, and through a study in a New Zealand rabbit liver model, found that the nuclides were aggregated in the liver in the form of microspheres after ${ }^{131}$ I-GMSS administration. In addition, radioactivity was detected 48 days after injection of ${ }^{131}$ IGMS, and the microspheres were degraded to different extents 24,32 , and 48 days after the injection of ${ }^{131}$ I-GMSS. Although these microspheres offer high activity and degradability, they are primarily limited to basic research at the animal level, and few radioactive microspheres can be applied in human clinical practice.

The most commonly used clinical radiation microspheres are radioactive ${ }^{90} \mathrm{Y}$ microspheres. They can be injected into tumor lesions through digital subtraction angiography (DSA) superselection, and the $\beta$-rays emitted by them can be used to kill tumors and perform endoradiotherapy (41-43). Theraspheres and SiR-spheres are available in the market. They are safe and efficacious for the treatment of TM. Several side effects are associated with trans-arterial procedures $(44,45)$ including dissociation of cargo and formation of ectopic embolism. Furthermore, since ${ }^{90} \mathrm{Y}$ only emits beta rays and cannot be detected by single-photon emission computed tomography/ positron emission tomography (SPECT/PET) imaging, it is difficult to obtain the drug distribution behavior in vivo by imaging techniques. There is a blind spot of the correlation between therapeutic effect and nuclide quantification. Thus, it is challenging to make unified clinical recommendations. ${ }^{90} \mathrm{Y}$ microsphere treatment is economically expensive, and thus widespread use of this treatment is quite limited.

\section{Others}

Other radiopharmaceutical carriers mainly include scaffolds, hydrogels, etc., such as the intensity-modulated radiationacrylic repositioning stent for the treatment of head and neck cancer reported by Lee Vsk et al. Retrospective cohort studies of patients with maxillary sinus, nasal, or oral cancer have revealed that acrylic repositioning stents do not alter radiotherapy outcomes and are highly stable (46). Zhu et al. (47) developed a biliary stent loaded with ${ }^{125} \mathrm{I}$ radioactive particles, and used a comparative clinical study of 23 patients to show that ${ }^{125}$ I seeds in the biliary stent not only improved the patency of the patients' biliary tract, but also prolonged the patients' survival time.
Hydrogels have become a hot research topic in recent years due to their excellent biocompatibility, biodegradability, and outstanding clinical application value $(48,49)$. Hydrogel carriers have also played an essential role in the study of cancer brachytherapy. For instance, Schaal et al. (50) used radionuclide ${ }^{131}$ I to label a thermal micelle composed of an elastin-like polypeptide (ELP) to form an in situ hydrogel brachytherapy of prostate cancer. The study was performed on a human PC-3M-Luc-C6 prostate tumor model and human BXPC3-Luc2 pancreatic tumor model and found that the ELP pool retained $52 \%$ and more than $70 \%$ of radioactivity for 60 days in prostate and pancreatic tumors, respectively. Furthermore, after $72 \mathrm{~h}$, there was no significant accumulation of radioactivity in the tissue outside the target ( $\leqq 0.1 \% \mathrm{ID})$; the median survival time of the two groups of nude mice was significantly extended.

Puente et al. (51) used an injectable chitosan hydrogel capable of releasing a chemotherapy drug (temozolomide, TMZ) while retaining a radioactive isotope preparation (iodine, ${ }^{131} \mathrm{I}$ ) as the carrier of intracavity local radiotherapy and chemotherapy for the intraperitoneal therapy of brain gliomas. Some studies have shown that injectable chemical-radio-hydrogel implants can potentially improve local control and overall prognosis of invasive, poor-prognosis brain tumors. Although some studies suggest that hydrogels have many advantages, they are still limited to basic research at the animal level. These materials have not been clinically translated due to defects in drug delivery and biological behavior.

\section{RADIOPHARMACEUTICAL DISPENSING AND FIXATION TECHNOLOGY}

The precise implementation of interventional brachytherapy is a significant clinical problem. The community needs to improve the dispensing efficiency and drug stability while also reducing the radiation injury to medical staff. This is an inevitable trend for nuclear medicine: Replacing manual operation with intelligent equipment $(52,53)$. The central dispensing systems are UG-05 (Japan), Medrad (United States), IRIS (Italy). However, such equipment has a single type of dispensing and is expensive.

Zhang et al. successfully developed a PET molecular imaging probe microfluidic modular integrated synthesis system for the above problems. The system uses a modular microfluidic chip strategy to synthesize different positron emission tomography (PET) molecular image probes on an instrument and achieve the chemical purity and radioactive chemical purity of online controller drugs (54). The precision instrument equipment not only dramatically expands individualization and increases the accuracy of medical PET clinical applications, but also plays a vital role in the research and development of related nuclear drugs and radiation protection applications. However, this equipment is not suitable for stable mixing of radiopharmaceuticals and interventional embolic agents (such as lipiodol) commonly used in the clinic. Given this, Liu 's team $(55,56)$ from Xiamen 
University developed a green, chemically free, super-stable homogeneous lipiodol formulation technology (SHIFT) (Figure 2). This technology makes the reactor reach the state of supercritical fluid by adjusting the temperature and pressure in the reactor. One can then adjust the physical parameters such as temperature and pressure to adjust the intermolecular force of the drug. This technology not only improves the solubility of drug molecules in lipiodol, but also achieves a homogeneous and stable state for several months to offer long-term fixation of radioactive drugs and interventional embolization agents.

\section{PRECISION DELIVERY SYSTEM OF INTERVENTIONAL SURGERY ROBOTS}

Interventional radiation therapy could be completed by an intelligent operating system. In fact, the manual operation based on experience is expected to be replaced by artificial intelligence. In order to solve the fundamental problems facing interventional radiation therapy such as intelligent precise delivery, current research mainly focuses on operator design choices, forced sensing information feedback, master-slave control methods, artificial intelligence algorithms, and the application of medical image analysis. Precision interventional robotic systems mainly include vascular interventional robot systems and particle-implantation robotic systems.

\section{Vascular Interventional Robotic System}

The Hansen Sensei ${ }^{\circledR}$ robotic system for percutaneous coronary intervention and percutaneous radiofrequency ablation was launched by Hansen Medical Inc. (Mountain View, CA, USA). It facilitates the entry and exit of the electrode conduit through the contact rolling of the friction wheel. It offers a circumferential rotation of the front end of the conduit by rotating the clamping device at the end of the conduit (57). For peripheral vascular interventional (PVI), a guidewire and a catheter should be used for drug injection. To address this, Hansen Medical Inc. updated its Magellan ${ }^{\circledR}$ robotic system by adding a set of friction band components in contact with each other. They use relative friction and rolling to achieve feed rotation of the guidewire. Versus the Artisan catheter, the Magellan system is an intelligent catheter that is more refined in diameter and has better angulation with tip force feedback. The major problem with this system is that the operation requires the use of a specific catheter, and the cost of a single operation is high (58).

The CorPath ${ }^{\circledR}$ GRX robot launched by Corindus Vascular Robotics Inc. (Waltham, MA, USA) is currently the only robot platform globally that can be used for PCI and PVI treatment at the same time. This robotic system manipulates the guidewire to complete the rotation and twist action of the feed by rolling and rotating the holding chamber through multiple sets of friction wheels. It then performs the rotation and feeds the guidewire through a gear transmission mechanism with position movement controlled by the manipulator's arm. However, the current

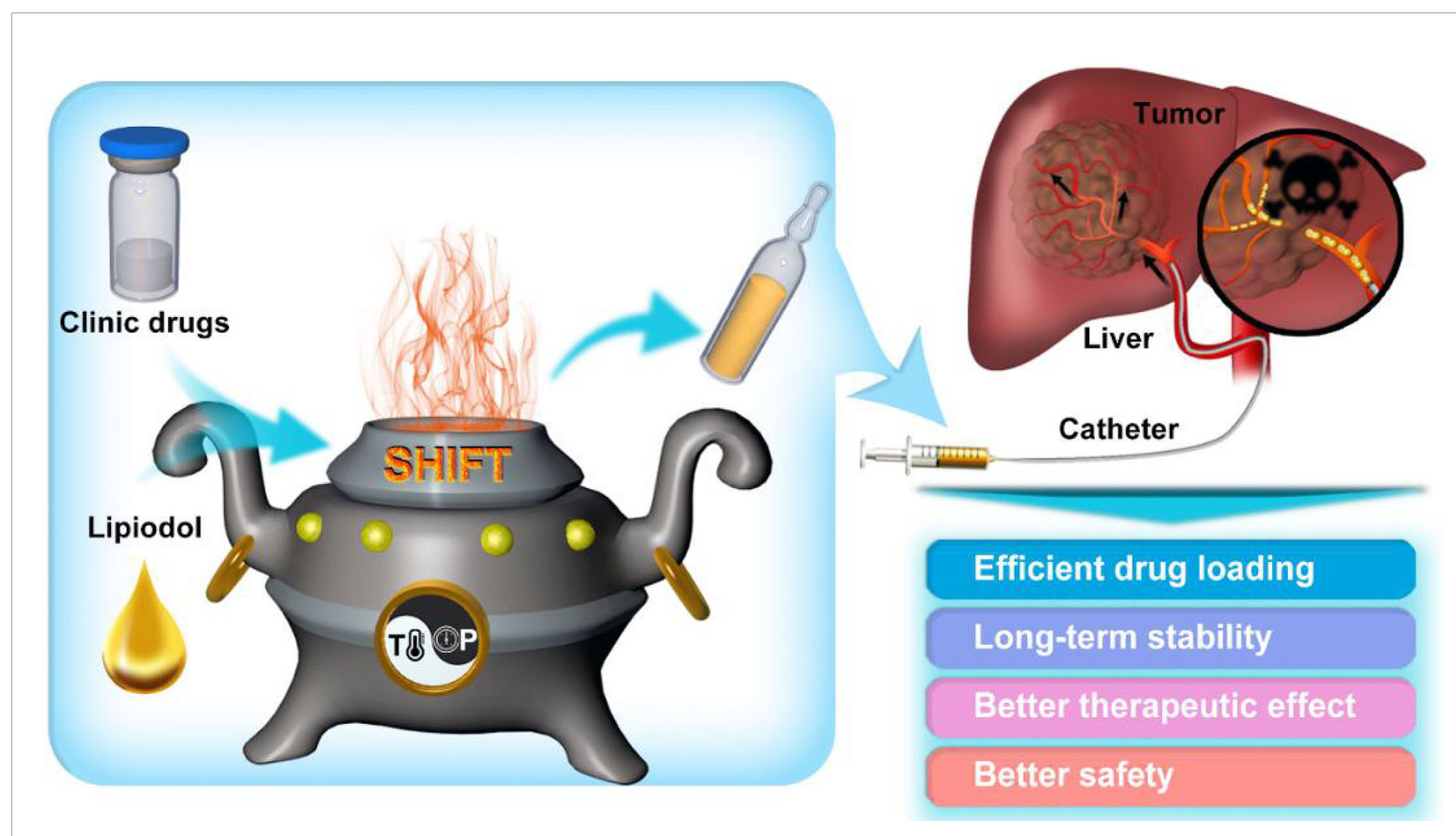

FIGURE 2 | Schematic illustration of super-stable homogeneous lipiodol formulation technology (SHIFT) as a revolutionary strategy for transhepatic arterial chemotherapy and embolization (TACE). The clinic drugs and lipiodol are introduced to develop formulations with SHIFT at a controlled temperature and pressure overcoming current challenges in the hepatocellular carcinoma (HCC) treatment with TACE. (Reprinted with permission from Liu et al. (56). Copyright Elsevier B.V). 
CorPath ${ }^{\circledR}$ system still lacks the main end control mode. It can only facilitate the remote end speed of the guidewire tube delivery through the handle $(22,59)$.

In 2019, the French company Robocath SAS(Rouen France) launched the R-One ${ }^{\circledR}$ robotic system for remote cardiovascular interventional therapy. The system can be used for remote delivery of coronary stents in PCI procedures. The robot is designed with a hinged open-close holding pod similar to that of CorPath ${ }^{\circledR}$. However, its main-end controller can only control the execution end speed and lacks force feedback design (60).

Yang et al. conducted in-depth research on artificial intelligence. Rafi-Tari found potential operation skills of interventional surgery through an artificial intelligence framework that made the operation of the surgical robot smoother and more stable. They eventually completed the surgical task in an experiment $(61,62)$. Chi et al. proposed using artificial intelligence to enable the interventional surgery robot to learn from the demonstration of the operation by experts to complete the operation independently or explore autonomously within the vascular model to try to accomplish the surgical goals. The experimental results showed that artificial intelligence could achieve this goal and a more accurate and smoother operation process than manual operation (63-66).

\section{Particle Implantation Robot System}

The Elekta-Nucletron FIRST system from Elekta-Nucletron AB (Stockholm, Sweden) includes an integrated real-time particle therapy system (FIRST $^{\mathrm{TM}}$ ) with robot-assisted needle recovery and particle pushing devices. The system includes a computercontrolled three-dimensional (3D) transrectal ultrasound system, an integrated puncture and particle delivery device, and an integrated treatment planning system. The surgical robot was certified by the US FDA and Health Canada in 2001 and by the European Community (EC or CE) in 2002 for use only in treating prostate cancer with particle implantation (67).

The MIRA-V system $(68,69)$ was developed at the University of Western Ontario, Canada and is an ultrasound-guided minimally invasive robot-assisted particle implantation system for the lung. The robot carries lung dose planning software upgraded from the Prostate Particle Implantation Planning System to improve the accuracy of the execution plan (70). It also has an optical camera and a 5DOF electromagnetic tracer sensor that can monitor the position of the puncture needle tip. However, the system is still in the laboratory stage and has not been reported in clinical application. Recently, a multi-organ particle implantation surgical robot (Para-Brachyrob system) was developed by the Research Center for Industrial Robots Simulation and Testing (CESTER), Technical University of Cluj-Napoca (Cluj-Napoca, Romania) for high-dose-rate brachytherapy (71). It is still in the experimental stage and has not yet received US FDA or CE approval.

\section{DISCUSSION}

To summarize, research on precision interventional brachytherapy of malignant tumors has led to significant advances in the types, functions, choices, and quality of radionuclides and their carriers in radiotherapy. However, most nuclides and carriers with excellent performance are still in the basic research and animal study stage. Future efforts include optimizing the performance of existing nuclides and carriers, stabilizing the nuclides in the lesion area for a long time, improving the efficiency and safety of their use, and clinical applications.

In addition, as the key to the accurate delivery of interventional radiotherapy for malignant tumors, the interventional surgical robot has initially achieved image guidance at the technical level and realized preoperative planning, puncture, and drug configuration automatically or semi-automatically. However, clinical applications, to date, have been limited: (1) Indications are narrow. Most interventional surgical robots operate on patients with specific tumors, and surgical robots involving other malignant tumors are still in the laboratory stage. (2) The image guidance system is single-mode. Existing equipment mainly uses ultrasound, computed tomography (CT), or magnetic resonance (MR) imaging to guide implantation. There is no surgical robot with a multi-mode imaging system to guide the implantation process; thus, it is impossible to map the radiopharmaceutical distribution and pressure-gated feedback in real-time accurately. (3) The robotic system is not intelligent enough. It has not achieved the master-slave robot macro/micro composite drive or an operating system with multi-channel control feedbacks such as vision, force, and touch (haptics).

\section{AUTHOR CONTRIBUTIONS}

PH and SG drafted the article. ER, HWC, HC, YP, BLuo, and YX devised the concept for the mini-review along with BLi, JL, JM, and GL. All authors revised and contributed to the final version of the manuscript. PH, SG, BLi, JL, JM, and GL contributed with critical revision of the manuscript throughout the process. All authors contributed to the article and approved the submitted version.

\section{FUNDING}

This work was supported by the Major State Basic Research Development Program of China (2017YFA0205201), the National Natural Science Foundation of China (81925019, $81603015,81871404,82003147$, and U1705281), the Fundamental Research Funds for the Central Universities (20720190088 and 20720200019), the Nuclear Medicine and Molecular Imaging Key Laboratory of Sichuan province open project (nos.HYX20003), and the Chengdu Gaoxin Medical Association 2020 Annual Cancer Intervention Special Research Fund (2020S02). 


\section{REFERENCES}

1. Sung H, Ferlay J, Siegel RL, Laversanne M, Soerjomataram I, Jemal A, et al. Global Cancer Statistics 2020: GLOBOCAN Estimates of Incidence and Mortality Worldwide for 36 Cancers in 185 Countries. CA Cancer J Clin (2021) 71:209-49. doi: 10.3322/caac.21660

2. Fan W, Yung B, Huang P, Chen X. Nanotechnology for Multimodal Synergistic Cancer Therapy. Chem Rev (2017) 117:13566-638. doi: 10.1021/ acs.chemrev.7b00258

3. Chu C, Lin H, Liu H, Wang X, Wang J, Zhang P, et al. Tumor Microenvironment-Triggered Supramolecular System as an In Situ Nanotheranostic Generator for Cancer Phototherapy. Adv Mater (2017) 29:10.1002/adma.20160592. doi: 10.1002/adma.201605928

4. Wyld L, Audisio RA, Poston GJ. The Evolution of Cancer Surgery and Future Perspectives. Nat Rev Clin Oncol (2015) 12:115-24. doi: 10.1038/ nrclinonc.2014.191

5. Vatner RE, Cooper BT, Vanpouille-Box C, Demaria S, Formenti SC. Combinations of Immunotherapy and Radiation in Cancer Therapy. Front Oncol (2014) 4:325. doi: 10.3389/fonc.2014.00325

6. Liu Y, Bhattarai P, Dai Z, Chen X. Photothermal Therapy and Photoacoustic Imaging via Nanotheranostics in Fighting Cancer. Chem Soc Rev (2019) 48:2053-108. doi: 10.1039/c8cs00618k

7. Zhang Q, Bao C, Cai X, Jin L, Sun L, Lang Y, et al. Sonodynamic TherapyAssisted Immunotherapy: A Novel Modality for Cancer Treatment. Cancer Sci (2018) 109:1330-45. doi: 10.1111/cas.13578

8. Yang Y, Yuan G, Zhan C, Huang Y, Zhao M, Yang X, et al. Benefits of Surgery in the Multimodality Treatment of Stage IIB-IIIC Small Cell Lung Cancer. J Cancer (2019) 10:5404-12. doi: 10.7150/jca.31202

9. Schwartsburd P. A View on Pathogenesis of $\ll$ Vicious Cancer Progression Cycle». Front Oncol (2020) 10:690. doi: 10.3389/fonc.2020.00690

10. Quail DF, Joyce JA. Microenvironmental Regulation of Tumor Progression and Metastasis. Nat Med (2013) 19:1423-37. doi: 10.1038/nm.3394

11. Klein CA. Cancer Progression and the Invisible Phase of Metastatic Colonization. Nat Rev Cancer (2020) 20:681-94. doi: 10.1038/s41568-02000300-6

12. Todd I. Fundamentals of Radiation Therapy and Cancer Chemotherapy. $\mathrm{Br} \mathrm{J}$ Cancer (1975) 31:700. doi: 10.1038/bjc.1975.121

13. Martin OA, Martin RF. Cancer Radiotherapy: Understanding the Price of Tumor Eradication. Front Cell Dev Biol (2020) 8:261. doi: 10.3389/ fcell.2020.00261

14. Lang JY. Review, Rellection and Prospect of Radiotherapy in China in the Past 30 Years. J Canc Control Treat (2017) 30:1-4.

15. Hellevik T, Martinez-Zubiaurre I. Radiotherapy and the Tumor Stroma: The Importance of Dose and Fractionation. Front Oncol (2014) 4:1. doi: 10.3389/ fonc.2014.00001

16. Adamus-Górka M, Mavroidis P, Lind BK, Brahme A. Comparison of Dose Response Models for Predicting Normal Tissue Complications From Cancer Radiotherapy: Application in Rat Spinal Cord. Cancers (Basel) (2011) 3:242143. doi: $10.3390 /$ cancers 3022421

17. Huang CC, Chao PJ, Guo SS, Wang CJ, Luo HL, Su YL, et al. Developing a Multivariable Normal Tissue Complication Probability Model to Predict Late Rectal Bleeding Following Intensity-Modulated Radiation Therapy. J Cancer (2019) 10:2588-93. doi: 10.7150/jca.29606

18. Bibok A, Doros A. Role of Interventional Radiological Procedures in the Treatment of Liver Cancer. Magy Onkol (2018) 62:45-52.

19. Piron L, Cassinotto C, Guiu B. Prise En Charge Des Tumeurs Malignes Du Foie En Radiologie Interventionnelle [Interventional Radiology of Liver Tumors]. Presse Med (2019) 48:1156-68. doi: 10.1016/j.lpm.2019.10.010

20. Boyvat F. Interventional Radiologic Treatment of Hepatocellular Carcinoma. Exp Clin Transpl (2017) 15:25-30. doi: 10.6002/ect.TOND16

21. Yang WC, Hsu FM, Yang PC. Precision Radiotherapy for non-Small Cell Lung Cancer. J BioMed Sci (2020) 27:82. doi: 10.1186/s12929-020-00676-5

22. Granada JF, Delgado JA, Uribe MP, Fernandez A, Blanco G, Leon MB, et al. First-In-Human Evaluation of a Novel Robotic-Assisted Coronary Angioplasty System. JACC Cardiovasc Interv (2011) 4:460-5. doi: 10.1016/ j.jcin.2010.12.007

23. Skowronek J. Current Status of Brachytherapy in Cancer Treatment-Short Overview. J Contemp Brachyther (2017) 9:581-9. doi: 10.5114/jcb.2017.72607
24. Dobrzynska MM. Maria Sklodowska-Curie, Her Life and Work-the 150 Anniversary of Her Birthday. Rocz Panstw Zakl Hig (2017) 68:309-12.

25. D’Addessi A, Racioppi M, Giustacchini M, Alcini A, Alcini E. ${ }^{125}$ I Seeds Implantation Plus Pelvic Lymphadenectomy in the Management of Localized Prostate Cancer. Minerva Urol Nefrol (1995) 47:105-11.

26. Peng S, Yang QX, Zhang T, Lu MJ, Yang G, Liu ZY, et al. Lobaplatin-TACE Combined With Radioactive ${ }^{125}$ I Seed Implantation for Treatment of Primary Hepatocellular Carcinoma. Asian Pac J Cancer Prev (2014) 15:5155-60. doi: 10.7314/apjcp.2014.15.13.5155

27. Cheng J, Ma S, Yang G, Wang L, Hou W. The Mechanism of Computed Tomography-Guided ${ }^{125}$ i Particle in Treating Lung Cancer. Med Sci Monit (2017) 23:292-9. doi: 10.12659/msm.898526

28. Martin RF, Bradley TR, Hodgson GS. Cytotoxicity of an ${ }^{125}$ I-Labeled DNABinding Compound That Induces Double-Stranded DNA Breaks. Cancer Res (1979) 39(8):3244-7.

29. Peschel RE, Colberg JW. Surgery, Brachytherapy, and External-Beam Radiotherapy for Early Prostate Cancer. Lancet Oncol (2003) 4:233-41. doi: 10.1016/s1470-2045(03)01035-0

30. Keisari Y, Kelson I. The Potentiation of Anti-Tumor Immunity by Tumor Abolition With Alpha Particles, Protons, or Carbon Ion Radiation and Its Enforcement by Combination With Immunoadjuvants or Inhibitors of Immune Suppressor Cells and Checkpoint Molecules. Cells (2021) 10:228. doi: 10.3390/cells10020228

31. Marwaha G, Macklis R, Singh AD, Wilkinson A. Brachytherapy. Dev Ophthalmol (2013) 52:29-35. doi: 10.1159/000351053

32. Ahmadzadehfar H, Biersack HJ, Ezziddin S. Radioembolization of Liver Tumors With Yttrium-90 Microspheres. Semin Nucl Med (2010) 40:105. doi: 10.1053/j.semnuclmed

33. De Ruyck K, Lambert B, Bacher K, Gemmel F, De Vos F, Vral A, et al. 188ReHDD/lipiodol Therapy for Hepatocellular Carcinoma: An Activity Escalation Study. Eur J Nucl Med Mol Imaging (2004) 33:344.

34. Pillai MR, Chakraborty S, Das T, Venkatesh M, Ramamoorthy N. Production Logistics of ${ }^{177} \mathrm{Lu}$ for Radionuclide Therapy. Appl Radiat Isot (2003) 59:109. doi: 10.1016/s0969-8043(03)00158-1

35. Chakraborty S, Das T, Sarma HD, Venkatesh M, Banerjee S. Preparation and Preliminary Studies on ${ }^{177} \mathrm{Lu}$-Labeled Hydroxyapatite Particles for Possible Use in the Therapy of Liver Cancer. Nucl MedBiol (2008) 35:589. doi: 10.1016/ j.nucmedbio.2008.03.003

36. Subramanian S, Das T, Chakraborty S, Sarma HD, Banerjee S, Samuel G, et al. Preparation of ${ }^{177} \mathrm{Lu}$-Labeled Oxine in Lipiodol as a Possible Agent for Therapy of Hepatocellular Carcinoma: A Preliminary Animal Study. Cancer Biother Radiopharm (2010) 25:539-43. doi: 10.1089/cbr.2010.0792

37. Sinha VR, Goyel V, Trehan A. Radioactive Microspheres in Therapeutics. Pharmazie (2004) 59:419-26.

38. Arranja AG, Hennink WE, Chassagne C, Denkova AG, Nijsen JFW. Preparation and Characterization of Inorganic Radioactive Holmium-166 Microspheres for Internal Radionuclide Therapy. Mater Sci Eng C Mater Biol Appl (2020) 106:110244. doi: 10.1016/j.msec.2019.110244

39. Zielhuis SW, Seppenwoolde JH, Bakker CJ, Jahnz U, Zonnenberg BA, van het Schip AD, et al. Characterization of Holmium Loaded Alginate Microspheres for Multimodality Imaging and Therapeutic Applications. J BioMed Mater Res A (2007) 82:892-8. doi: 10.1002/jbm.a.31183

40. Ma Y, Wan Y, Luo DH, Duan LG, Li L, Xia CQ, et al. Direct In Vivo Injection of ${ }^{131}$ I-GMS and its Distribution and Excretion in Rabbit. World $J$ Gastroenterol (2010) 16:2120-8. doi: 10.3748/wjg.v16.i17.2120

41. Subbiah V, Murthy R, Anderson PM. [90Y]Yttrium Microspheres Radioembolo-Therapy in Desmoplastic Small Round Cell Tumor Hepatic Metastases. J Clin Oncol (2011) 29:e292-4. doi: 10.1200/JCO.2010.32.4673

42. Brown KT, Do RK, Gonen M, Covey AM, Getrajdman GI, Sofocleous CT, et al. Randomized Trial of Hepatic Artery Embolization for Hepatocellular Carcinoma Using Doxorubicin-Eluting Microspheres Compared With Embolization With Microspheres Alone. J Clin Oncol (2016) 34:2046-53. doi: 10.1200/JCO.2015.64.0821

43. Mikell JK, Mahvash A, Siman W, Mourtada F, Kappadath SC. Comparing Voxel-Based Absorbed Dosimetry Methods in Tumors, Liver, Lung, and at the Liver-Lung Interface for (90)Y Microsphere Selective Internal Radiation Therapy. EJNMMI Phys (2015) 2:16. doi: 10.1186/s40658-015-0119-y

44. Helmberger T, Golfieri R, Pech M, Pfammatter T, Arnold D, Cianni R, et al. Clinical Application of Trans-Arterial Radioembolization in Hepatic 
Malignancies in Europe: First Results From the Prospective Multicentre Observational Study CIRSE Registry for SIR-Spheres Therapy (CIRT). Cardiovasc Intervent Radiol (2021) 44:21-35. doi: 10.1007/s00270-02002642-y

45. Riaz A, Awais R, Salem R. Side Effects of Yttrium-90 Radioembolization. Front Oncol (2014) 4:198. doi: 10.3389/fonc.2014.00198

46. Lee VSK, Nguyen CT, Wu J. The Fabrication of an Acrylic Repositioning Stent for Use During Intensity Modulated Radiation Therapy: A Feasibility Study. J Prosthodont (2019) 28:643-8. doi: 10.1111/jopr.13074

47. Zhu HD, Guo JH, Huang M, Ji JS, Xu H, Lu J, et al. Irradiation Stents vs. Conventional Metal Stents for Unresectable Malignant Biliary Obstruction: A Multicenter Trial. J Hepatol (2018) 68:970-7. doi: 10.1016/j.jhep.2017.12.028

48. Singhal A, Sinha N, Kumari P, Purkayastha M. Synthesis and Applications of Hydrogels in Cancer Therapy. Anticancer Agents Med Chem (2020) 20:143146. doi: $10.2174 / 1871521409666200120094048$

49. Cai Y, Zheng C, Xiong F, Ran W, Zhai Y, Zhu HH, et al. Recent Progress in the Design and Application of Supramolecular Peptide Hydrogels in Cancer Therapy. Adv Healthc Mater (2021) 10:e2001239. doi: 10.1002/adhm.202001239

50. Schaal JL, Li X, Mastria E, Bhattacharyya J, Zalutsky MR, Chilkoti A, et al. Injectable Polypeptide Micelles That Form Radiation Crosslinked Hydrogels in Situ for Intratumoral Radiotherapy. J Control Release (2016) 228:58-66. doi: 10.1016/j.jconrel.2016.02.040

51. Puente P, Fettig N, Luderer MJ, Jin A, Shah S, Muz B, et al. Injectable Hydrogels for Localized Chemotherapy and Radiotherapy in Brain Tumors. J Pharm Sci (2018) 107:922-33. doi: 10.1016/j.xphs.2017.10.042

52. Wang C, Zhu X, Hong JC, Zheng D. Artificial Intelligence in Radiotherapy Treatment Planning: Present and Future. Technol Cancer Res Treat (2019) 18:1533033819873922. doi: 10.1177/1533033819873922

53. Akmal JS, Salmi M, Mäkitie A, Björkstrand R, Partanen J. Implementation of Industrial Additive Manufacturing: Intelligent Implants and Drug Delivery Systems. J Funct Biomater (2018) 9:41. doi: 10.3390/jfb9030041

54. Lei M, Pan JZ, Xu GM, Du PZ, Tian M, Zhang H. Automated Microfluidic Chip System for Radiosynthesis of PET Imaging Probes. J Zhejiang Univ Sci B (2019) 20:865-7. doi: 10.1631/jzus.B1900535

55. Chen H, Cheng HW, Wu WY, Li DF, Mao JS, Chu CC, et al. The Blooming Intersection of Transcatheter Hepatic Artery Chemoembolization and Nanomedicine. Chin Chem Lett (2020) 31:1375-81. doi: 10.1016/j.cclet. 2020.03.024

56. Cheng HW, Yang XM, Liu G. Superstable Homogeneous Iodinated Formulation Technology: Revolutionizing Transcatheter Arterial Chemoembolization. Sci Bull (2020) 65:1685-7. doi: 10.1016/j.scib.2020.06.029

57. Saliba W, Cummings JE, Oh S, Zhang Y, Mazgalev TN, Schweikert RA, et al. Novel Robotic Catheter Remote Control System: Feasibility and Safety of Transseptal Puncture and Endocardial Catheter Navigation. J Cardiovasc Electrophysiol (2006) 17:1102-5. doi: 10.1111/j.1540-8167.2006.00556.x

58. Riga CV, Bicknell CD, Rolls A, Cheshire NJ, Hamady MS. Robot-Assisted Fenestrated Endovascular Aneurysm Repair (FEVAR) Using the Magellan System. J Vasc Interventional Radiol (2013) 24:191-6. doi: 10.1016/ j.jvir.2012.10.006

59. Al Nooryani A, Aboushokka W. Rotate-On-Retract Procedural Automation for Robotic-Assisted Percutaneous Coronary Intervention: First Clinical Experience. Case Rep Cardiol (2018) 2018:6086034. doi: 10.1155/2018/ 6086034

60. Buzurovic I, Podder TK, Yu Y. Prediction Control for Brachytherapy Robotic System. J Robot (2010) 2010:10. doi: 10.1155/2010/581840

61. Rafii-Tari H, Liu J, Payne CJ, Bicknell C, Yang GZ. Hierarchical HMM Based Learning of Navigation Primitives for Cooperative Robotic Endovascular
Catheterization. Med Image Comput Comput Assist Interv (2014) 17:496503. doi: 10.1007/978-3-319-10404-1_62

62. Rafii-Tari H, Liu J, Lee SL, Bicknell C, Yang GZ. Learning-Based Modeling of Endovascular Navigation for Collaborative Robotic Catheterization. Med Image Comput Comput Assist Interv (2013) 16:369-77. doi: 10.1007/978-3642-40763-5_46

63. Chi W, Dagnino G, Kwok TM. Collaborative Robot-Assisted Endovascular Catheterization With Generative Adversarial Imitation Learning; Proceedings of the 2020 IEEE International Conference on Robotics and Automation (ICRA). IEEE (2020). doi: 10.1109/ICRA40945.2020.9196912

64. Chi W, Liu J, Rafii-Tari H, Riga C, Bicknell C, Yang GZ, et al. Learning-Based Endovascular Navigation Through the Use of Non-Rigid Registration for Collaborative Robotic Catheterization. Int J Comput Assist Radiol Surg (2018) 13:855-64. doi: 10.1007/s11548-018-1743-5

65. Chi W, Liu J, Abdelaziz ME. Trajectory Optimization of Robot-Assisted Endovascular Catheterization With Reinforcement Learning; Proceedings of the 2018 IEEE/RSJ International Conference on Intelligent Robots and Systems (IROS). F IEEE (2018).

66. Rafii-tari H, Payne CJ, Yang G-Z. Current and Emerging Robot-Assisted Endovascular Catheterization Technologies: A Review. Ann Biomed Eng (2014) 42:697-715. doi: 10.1007/s10439-013-0946-8

67. Van Gellekom MP, Moerland MA, Wijrdeman HK, Battermann JJ. Quality of Permanent Prostate Implants Using Automated Delivery With Seedselectron Versus Manual Insertion of RAPID Strands. Radiother Oncol (2004) 73:49-56. doi: 10.1016/j.radonc.2004.08.004

68. Hungr N, Troccaz J, Zemiti N, Tripodi N. Design of an Ultrasound-Guided Robotic Brachytherapy Needle-Insertion System. Conf Proc IEEE Eng Med Biol Soc (2009) 2009:250-3. doi: 10.1109/IEMBS.2009.5333801

69. Podder TK, Beaulieu L, Caldwell B, Cormack RA, Crass JB, Dicker AP, et al. AAPM and GEC-ESTRO Guidelines for Image-Guided Robotic Brachytherapy: Report of Task Group 192. Med Phys (2014) 41:101501. doi: $10.1118 / 1.4895013$

70. Lin AW, Trejos AL, Mohan S, Bassan H, Kashigar A, Patel RV, et al. Electromagnetic Navigation Improves Minimally Invasive Robot-Assisted Lung Brachytherapy. Comput Aided Surg (2018) 13:114-23. doi: 10.3109/ 10929080801969725

71. Popescu T, Kacsó AC, Pisla D, Kacsó G. Brachytherapy Next Generation: Robotic Systems. J Contemp Brachyther (2015) 7:510-4. doi: 10.5114/ jcb.2015.56769

Conflict of Interest: The authors declare that the research was conducted in the absence of any commercial or financial relationships that could be construed as a potential conflict of interest.

Publisher's Note: All claims expressed in this article are solely those of the authors and do not necessarily represent those of their affiliated organizations, or those of the publisher, the editors and the reviewers. Any product that may be evaluated in this article, or claim that may be made by its manufacturer, is not guaranteed or endorsed by the publisher.

Copyright $\odot 2021$ He, Guan, Ren, Chen, Chen, Peng, Luo, Xiong, Li, Li, Mao and Liu. This is an open-access article distributed under the terms of the Creative Commons Attribution License (CC BY). The use, distribution or reproduction in other forums is permitted, provided the original author(s) and the copyright owner(s) are credited and that the original publication in this journal is cited, in accordance with accepted academic practice. No use, distribution or reproduction is permitted which does not comply with these terms. 